\title{
Burocracia e crescimento: uma análise internacional dos efeitos das estruturas do Estado "weberiano" sobre o crescimento econômico ${ }^{1}$
}

Peter Evans

Universidade da Califórnia, Berkeley (EUA)

James E. Rauch

Universidade da Califórnia, San Diego (EUA)

Tradução: Ricardo Avelar de Souza (Pangea Centro de Tradução, Interpretação e Idiomas Ltda)

O papel das estruturas da autoridade burocrática para a potencialização do crescimento econômico tem sido uma preocupação sociológica desde as contribuições clássicas de Max Weber, de quase 100 anos atrás. Utilizando um conjunto de dados recente e original, foram examinadas as características das principais instituições econômicas estatais e os registros de crescimento em uma amostra com 35 países em desenvolvimento durante o período compreendido entre 1970 e 1990. A "Escala de Weberianismo" utilizada oferece uma medida simples do grau no qual essas instituições empregam recrutamento meritocrático e oferecem carreiras estruturadas com progressão funcional e gratificação

\footnotetext{
${ }^{1}$ Texto originalmente publicado na American Sociological Review, v. 64, n. 5, out. 1999, p. 748-765, sob o título "Bureaucracy and Growth: A Cross-National Analysis of the Effects of 'Weberia' State Structures on Economic Growth". Os resultados desse trabalho são oriundos do projeto sobre a Estrutura Burocrática e Performance Econômica, dirigido por Peter Evans e James Rauch. O projeto foi financiado em vários estágios pela Fundação Russel Sage, pelo Centro para Reforma Institucional e Setor Informal, e pelo Departamento de Pesquisa Política do Banco Mundial. Nós agradecemos aos 126 especialistas nos países por sua generosidade em dividir seu conhecimento e expertise profissional. Os resultados relatados aqui foram produzidos por Linus Huang e John Tabolt, que trabalharam sob a direção de Peter Evans e James Rauch. Patrick Heller e Mark Ritchie forneceram uma ajuda imensurável nos estágios iniciais da análise de dados. Pelos comentários nas etapas iniciais deste paper, nós agradecemos a Ken Bollen, Meil Fligstein, Trond Petersen, e Erik Olin Wright. Christy Getz participou de maneira indispensável na revisão do manuscrito. Também agradecemos aos dois pareceristas anônimos e ao Editor ASR pelos seus comentários.
} 
de desempenho. Descobriu-se que essas características "weberianas" reforçam, significativamente, as perspectivas de crescimento econômico, mesmo quando controlamos os níveis iniciais de PIB per capita e capital humano. Os resultados indicam que essas características "weberianas" deveriam ser incluídas como um fator em modelos gerais de crescimento econômico. Eles também sugerem a necessidade de maior atenção, pelos policy makers, para a construção de burocracias aprimoradas; e de mais pesquisas, pelos cientistas sociais, sobre as variações em como as burocracias estatais se encontram organizadas.

\section{Bureaucracy and Growth: A Cross-National Analysis of the Effects of 'Weberian' State Structures on Economic Growth}

The role of bureaucratic authority structures in facilitating economic growth has been a sociological concern since Max Weber's classic contributions al-most 100 years ago. Using a recent and original data set, we examine the characteristics of core state economic agencies and the growth records of a sample of 35 developing countries for the 1970-1990 period. Our "Weberianness Scale" offers a simple measure of the degree to which these agencies employ meritocratic recruitment and offer predictable, rewarding long-term careers. We find that these "Weberian" characteristics significantly enhance prospects for economic growth, even when we control for initial levels of GDP per capita and human capital. Our results imply that "Weberianness" should be included as a factor in general models of economic growth. They also suggest the need for more attention by policymakers to building better bureaucracies and more research by social scientists on variations in how state bureaucracies are organized. 
Explicar transformações econômicas em nível nacional é uma preocupação sociológica clássica, bem como objeto central da análise econômica. Existem várias maneiras de abordar essa tarefa. Contudo, uma das mais desafiadoras envolve a tentativa de analisar o papel que as instituições públicas têm no fomento (ou impedimento) do crescimento econômico.

O crescimento depende de governança. Decifrar a relação entre as estruturas administrativas e os níveis cambiantes de produção econômica é, portanto, uma preocupação constante tanto dos teóricos quanto dos empíricos. Em 1997, o Banco Mundial tomou novamente para si essa tarefa mediante um Relatório do Desenvolvimento Mundial chamado "O Estado em um mundo mutável". Tanto a escolha do tema quanto o conteúdo do relatório significaram uma importante mudança no pensamento sobre o papel do Estado dentro do "status quo do desenvolvimento". Explicar por que alguns Estados burocráticos são mais eficientes que outros parece ter mais importância que a condenação de excessos vinculados à intervenção estatal. A adoção dessa pauta demanda que tornemos a explorar os argumentos clássicos sobre a eficácia comparativa das diferentes formas de organização administrativa. É, sem dúvida, uma oportunidade para a sociologia contribuir para o entendimento das diferenças internacionais nas taxas de crescimento econômico.

Entre os argumentos clássicos que precisam ser considerados, em conjunto com evidências sistematicamente comparadas, a análise de Weber sobre a burocracia é talvez o mais forte candidato para tal. No começo do século, Weber ([1904-1911] 1968), em seus ensaios em Economia e Sociedade, argumentou em defesa do valor fundamental da burocracia como uma das fundações institucionais do crescimento capitalista. Subsequentes análises históricas comparativas (p. ex.: PolanYı, [1944] 1957) reverberaram as afirmações de Weber, mas a tese da "burocracia como ferramenta de crescimento" teve sempre que bater-se contra a visão smithiana, historicamente anterior e ideologicamente poderosa, de que o governo, independentemente de sua forma organizacional, era inimigo do crescimento, tão logo sua ação perpassasse a proteção dos direitos de propriedade².

Nos anos 1970 e 1980, a economia política neoclássica e a análise da escolha racional forneciam um novo reforço analítico para a perspectiva smithiana (cf. Buchanan, Toluson, e Tullock, 1980; Colclough e Manor, 1991; Collander, 1984; Krueger, 1974).

\footnotetext{
2 Por "smithiana" entende-se a visão comumente entendida de "laissez-faire" do papel do governo que é usualmente atribuída a Adam Smith. A visão de Smith era, na verdade, mais sofisticada, incluindo, por exemplo, uma apreciação da importância da provisão pública de uma escala de bens coletivos.
} 
Estudos de caso sobre rent-seeking e sobre Estados "predatórios" complementaram esses argumentos analíticos com embasamento empírico igualmente forte (p. ex., Bates, 1981; KlitgaARd, 1988). Infelizmente, na pressa de evitar os perigos da intervenção estatal, a questão sobre quais estruturas de Estado são melhores para promover o crescimento econômico foi facilmente esquecida.

Contudo, a partir dos anos 1990, economistas (e não os sociólogos, como seria de se imaginar) começaram a debruçar-se sobre os dados internacionais que demonstravam a importância de examinar melhor a organização dos Estados. Seus resultados mostraram diversas medidas de "qualidade governamental" que estariam fortemente associadas ao crescimento econômico (KNACK e KeEfer 1995; MaURo 1995). Essa literatura, que crescia rapidamente, sugeriu que as visões neoclássicas de desempenho governamental eram, por demais, simplistas. No entanto, talvez devido à ausência de sociólogos na discussão, carecia ainda de um modo para descrever o que seria um "bom governo".

Análises empíricas contemporâneas de rent-seeking e corrupção frequentemente empregam o termo "burocracia" em sua conotação pejorativa comumente encontrada no cotidiano, em vez do sentido weberiano de um conjunto de organizações administrativas com características estruturais específicas. Weber entendia a burocracia como um tipo de estrutura organizacional especial, estabelecida em contraste às antigas formas de governo patrimonial e prebendária, e não como um amontoado de agentes do Estado.

A perspectiva weberiana não nega os efeitos positivos do fortalecimento de instituições de mercado, mas ela postula que as organizações públicas burocraticamente estruturadas, usando seu conjunto próprio de procedimentos de tomada de decisão, são um complemento necessário aos arranjos institucionais baseados no mercado ${ }^{3}$. Mais precisamente, Weber argumentou que organizações administrativas públicas caracterizadas por recrutamento meritocrático e por carreiras estruturadas com progressão funcional e gratificação de desempenho serão mais eficientes na facilitação do crescimento capitalista do que outras formas de organização estatal. Essa hipótese não pode ser dispensada pelo simples fato da descoberta de que as pessoas que se denominam burocratas tenham envolvimento em movimentos para obtenção de favoritismo político ou que

\footnotetext{
${ }^{3}$ O espírito da perspectiva weberiana é, pelo menos parcialmente, capturado nas asserções de cunho "novo institucionalista" de Williamson (1985) de que sistemas de produção complexos são os que provavelmente exigem a mistura (essencialmente não mercadológica) de estruturas governamentais com transações de mercado mais tradicionais. Mas a aplicação da perspectiva de Williamson tem sido geralmente limitada a análises sobre as relações entre firmas privadas e é raramente utilizada em estudos de burocracias estatais.
} 
governos corruptos tenham solapado o crescimento econômico. Abordar a "hipótese do estado weberiano" significa responder à seguinte pergunta: "Os países cujos aparatos administrativos aproximam-se mais de formas de organização burocrática são caracterizados por maiores taxas de crescimento econômico?". Por algum motivo, estudiosos do desenvolvimento econômico não têm encontrado os incentivos necessários para gerar uma resposta empírica sistemática para essa questão aparentemente simples. Nossa pesquisa representa um esforço inicial para preencher essa lacuna.

Usando um conjunto original de dados, examinamos o efeito sobre o crescimento econômico de certos aspectos estruturais que foram elementos-chave na caracterização original de burocracia para Weber. A "Escala de Weberianismo" aqui utilizada oferece uma medida simples do grau no qual as agências estatais centrais são caracterizadas pelo recrutamento meritocrático e oferecem carreiras estruturadas com progressão funcional e gratificação de desempenho.

\section{Literatura recente}

A literatura sobre o papel que o Estado burocrático tem ao promover ou atravancar o crescimento econômico varia entre estudos de casos detalhados sobre certas agências em certos países e análises internacionais que utilizaram representações estatísticas de muitos países. Tradicionalmente, os cientistas políticos dominaram a produção de estudos de caso (por exemplo, StePHAN, 1978; WATERBURY, 1983), enquanto os sociólogos focaram-se mais em análises internacionais (por exemplo, Delacroix e RAGIN, 1981; RubINSON, 1977; SNYDER e KICK, 1979). Recentemente, o interesse entre os economistas pelas análises internacionais expandiu substancialmente a produção de estudos internacionais estatísticos. O principal estímulo para esse renovado interesse foi o surgimento da "teoria de crescimento endógeno", que oferece apoio teórico formal para a proposição de que fatores institucionais podem ter efeito fundamental sobre as taxas de crescimento (cf. LuCAS, 1988; ver também, por exemplo, ROMER, 1986, 1990, 1994).

A perspectiva de crescimento endógeno legitimou um amplo conjunto de análises internacionais por intermédio de estudos realizados por economistas que examinaram o impacto de uma multiplicidade de variáveis não econômicas sobre as taxas de crescimento econômico (ver Crowley et al., 1998). Em um dos primeiros e mais influentes estudos, Barro (1991) enfatizou o papel negativo do governo, ao salientar o impacto negativo das despesas governamentais (como uma parte do PIB) sobre as taxas de crescimento.

O que a literatura sociológica precedente e a atual literatura econômica internacional não detinham era a possibilidade de abordar seriamente a questão 
de como variações na forma de organização governamental poderiam afetar o dinamismo econômico. Argumentos da literatura sociológica inicial foram formulados em termos do conceito dúbio de "força estatal", com as receitas e despesas governamentais oferecidas como indicadores para "força estatal" (p. ex., Rubinson, 1977). As regressões internacionais dos novos modelos de crescimento endógeno incluíram indicadores ainda mais insatisfatórios, como a utilização do número, com base anual, dos assassinatos ou revoluções como indicadores para a estabilidade política (BARRO, 1991).

Nem os economistas, nem os sociólogos (estranhamente) orientaram suas análises internacionais para as diferenças organizacionais. Contudo, desenvolveuse uma literatura que voltou a atenção para as estruturas burocráticas acordes à hipótese weberiana. Essa literatura foi construída em torno de estudos de caso detalhados sobre países individuais, e focou-se principalmente em uma única região. O clássico estudo de Johnson (1982) sobre o Ministério de Comércio Exterior e Indústria (Miti) do Japão durante os anos de ouro da industrialização japonesa liderou o caminho na área. O retrato traçado por Johnson foi, de forma surpreendente, consistente com a perspectiva weberiana. Estudos subsequentes sobre a Coreia (AMSDEN, 1989) e Taiwan (WADE, 1990) reforçaram essa nova literatura ${ }^{4}$. Devido ao fato de os "Tigres Asiáticos" descritos nesses estudos terem sido também as nações mais bem-sucedidas economicamente durante os anos 1970 e 1989, eles criaram um forte caso prima facie a favor da hipótese weberiana. No começo dos anos 1990, até mesmo o Banco Mundial (1993) pareceu juntar-se ao coro com seu relatório Milagre do Leste Asiático, que enfatizava o papel positivo das burocracias do Leste Asiático na espetacular industrialização da região (veja também Campos e Root, 1996; Cheng, Haggard e Kang, 1995; КoH, 1995; Quah, 1993). Entretanto, o argumento continuou a existir basicamente nos estudos de caso. Permanecia, então, a questão sobre a possibilidade de a hipótese weberiana ser substanciada com um conjunto maior de evidências sistemáticas.

Durante os anos 1990, a literatura de estudos de caso foi complementada por esforços para conectar variações no caráter de burocracias estatais ao desempenho econômico por meio de análises quantitativas internacionais. Economistas, em vez de sociólogos, assumiram a liderança no desenvolvimento de um foco mais organizacional. Um novo conjunto de estudos utilizou avaliações comercialmente

\footnotetext{
${ }^{4}$ Simultaneamente, outras literaturas complementares começaram a apontar os pontos fracos das instituições públicas como uma barreira principal para o crescimento na África subsaariana (cf. BATES, 1989; Callaghy, 1989; Easterly e Levine, 1997; Banco Mundial, 1994, 1997).
} 
disponíveis sobre variações nos governos nacionais, que vinham sendo utilizadas pelos empresários há algum tempo ${ }^{5}$ A validade metodológica e a confiabilidade dessas medidas encontravam-se abertas ao debate, já que os serviços de classificação que os proviam ofereciam pouca explicação sobre como seus dados eram obtidos ou por que razão eles deveriam ser considerados confiáveis. Os dados pareciam ser baseados principalmente nas avaliações de consultores, mas os fundamentos segundo os quais esses consultores eram selecionados não eram normalmente especificados, e questões metodológicas não eram, claramente, uma preocupação fundamental ${ }^{6}$. A validade dessas classificações, como determinantes independentes do crescimento econômico, também era suspeita. A maior parte dos componentes das classificações apresentava claramente polos "bons" e "ruins" - maior ou menor corrupção, maior ou menor burocracia, maior ou menor "qualidade" de burocracia, e assim por diante. Devido ao fato de que os avaliadores estavam cientes do desempenho econômico dos países que eles avaliavam, a tendência de atribuir "boas" classificações para países de alto desempenho e "más" classificações para os de baixo desempenho era como "construir" uma correlação entre as classificações e o crescimento econômico.

Apesar de suas falhas, essas classificações proporcionaram uma maneira de comparar burocracias através de um amplo conjunto de países, e elas pareceram produzir resultados que confirmaram a importância das variações através das burocracias nacionais, ao explicar variações no crescimento econômico. Mauro (1995), utilizando classificações sobre "corrupção" e "burocracia" da Business International, descobriu que a variação nessas classificações era significativamente associada a níveis elevados de investimento que, por sua vez, eram um dos mais óbvios e poderosos instrumentos de prognóstico de crescimento econômico. Knack e Keefer (1995) utilizaram as classificações do International Country Risk Guide (ICRG) e do Business and Environmental Risk Inteligence (Beri), e eles também descobriram que essas classificações estavam diretamente relacionadas a variações no crescimento da renda per capita ${ }^{7}$.

\footnotetext{
${ }^{5}$ International Country Risk Guide (ICRG), Business and Environmental Risk Inteligence (Beri), e Business International estão entre os mais proeminentes exemplos de tais avaliações.

${ }^{6}$ Do ponto de vista de um investidor procurando pela melhor avaliação atual sobre as perspectivas de retornos futuros em um determinado local, a principal vantagem dos dados fornecidos por esses serviços de classificação é sua pontualidade. ICRG, por exemplo, fornece classificações mensais para 130 países em uma variedade de indicadores políticos e econômicos. Nenhum estudo puramente acadêmico chegaria perto de oferecer tal informação tão imediatamente.

7 La Porta et al. (1999) oferece uma excelente discussão sobre a qualidade das instituições governamentais; porém, seu foco está orientado para os elementos determinantes da qualidade e do desempenho, em vez de focar-se nos seus efeitos sobre o crescimento econômico.
} 
O uso de dados sobre variações em burocracias estatais provê aos estudos recentes uma clara vantagem sobre os trabalhos anteriores, que tiveram que basear-se e confiar em medidas brutas, como despesas governamentais agregadas, ou indicadores genéricos, como o número de assassinatos. O fato de os estudos recentes encontrarem constantes correlações entre desempenho burocrático e crescimento econômico serve de alento para a tentativa de refinar a compreensão das raízes do "desempenho econômico". Contudo, mesmo essa nova geração de estudos continua prisioneira dos métodos disponíveis. Esforços convincentes para julgar a validade empírica da hipótese weberiana devem ser iniciados com informações sobre como a estrutura das burocracias estatais varia entre os países, que é o que, neste trabalho, tratamos de fazer.

\section{Conectando estruturas burocráticas e crescimento}

Análises contemporâneas das estruturas burocráticas comparativas necessitam ir além de Weber, porém as caracterizações de Weber oferecem um ponto de partida simples e acessível para pesquisas comparativas. Ao contrastar a burocracia com formas anteriores de organização, Weber salientou um número de pontos que podem ser empregados a fim de avaliar empiricamente dados de forma relativamente objetiva. Este trabalho enfatiza dois desses pontos. O primeiro é a importância do recrutamento meritocrático, que idealmente é baseado em uma combinação entre educação e verificação (GERTH e MılLs, 1958, p. 241; PARSONS, 1964, p. 333, 339). O segundo é uma evolução previsível para a carreira profissional, que proveja gratificações tangíveis e intangíveis de longo prazo para aqueles indivíduos recrutados para a burocracia (GERTH e Mills 1958, p. 200-203; Parsons, 1964, p. 334-335; StinchCombe, 1974). Poderíamos ter escolhido outras características weberianas ${ }^{8}$. Uma vantagem do recrutamento meritocrático e da gratificação/evolução previsível de carreira é que essas características são relativamente fáceis de serem traduzidas em simples medidas que podem ser avaliadas por vários países. Por isso, focar-se nelas facilita a realização de testes empíricos. Além disso, conexões teóricas plausíveis podem ser estabelecidas entre essas características e a habilidade organizacional melhorada para entregar os

\footnotetext{
${ }^{8}$ Porque as características escolhidas para o foco do trabalho consistem em um conjunto parcial daquelas descritas por Weber, salientar outras características pode produzir resultados diferentes. Por exemplo, tomada de decisão por regras, que é claramente uma característica do modelo burocrático, pode ser uma espada de dois gumes, melhorando a previsibilidade e eficiência até certo ponto, mas produzindo rigidez e esclerose organizacional quando continuada além do ponto. O mesmo argumento poderia ser aplicado à ideia de que cada escritório no aparato do Estado deveria mostrar âmbitos estritamente definidos e que não apresentassem sobreposição.
} 
bens coletivos que constituem a potencial contribuição do Estado para o crescimento econômico. O recrutamento meritocrático não só aumenta a probabilidade de garantir pelo menos um mínimo de competência, mas também ajuda a gerar coerência corporativa e esprit de corps, que, por sua vez, pode-se argumentar, possui efeitos substantivos na motivação dos indivíduos que atuam como servidores públicos. Burocratas que se veem como tendo se juntado aos seus confrères no poder, por virtude da posse de habilidades similares, são mais propensos a internalizar normas e objetivos compartilhados do que aqueles que sabem que devem seu cargo a um favor de um parente ou patrono em particular. A identificação com colegas e com a própria organização propicia também a internalização de custos intangíveis, aumentando a eficácia do monitoramento das atividades corruptas que subvertem os objetivos organizacionais.

Oferecer carreiras estruturadas com progressão funcional e gratificação de desempenho pode também aumentar a competência nesse longo prazo; contudo, independente de seus efeitos sobre a competência, tais carreiras aumentarão a coerência corporativa. Igualmente, a perspectiva previsível de gratificações de carreiras de longo prazo reduz a relativa atratividade de rápidos retornos disponíveis por meio das práticas de corrupção individuais. Isso é obvio na medida em que um dos aspectos das carreiras estruturadas com progressão funcional e gratificação de desempenho são os salários competitivos. É igualmente claro que as carreiras que oferecem a expectativa de várias promoções relacionadas ao desempenho e conformidade com as regras organizacionais criam desincentivos ao comportamento corrupto, especialmente se tal comportamento minar os objetivos da organização. Os custos de quebrar as regras da organização são diretamente proporcionais à longevidade esperada de participação na organização e às gratificações esperadas para a longevidade ${ }^{9}$. Em geral, recrutamento meritocrático e evolução previsível de carreiras deveriam ajudar a estruturar os incentivos dos burocratas individuais, de modo que haja melhoria na habilidade da organização que eles administram para buscar, de modo efetivo, os objetivos de longo prazo ${ }^{10}$.

\footnotetext{
${ }^{9}$ Stinchcombe $(1974$, p. $134-135,147-148)$ foca no meio industrial em vez das burocracias administrativas, porém fornece uma relevante análise do papel das carreiras na formação de motivações individuais.

${ }^{10}$ Recrutamento meritocrático e evolução de carreiras não são as únicas características estruturais que podem ser postuladas para melhorar o desempenho organizacional de burocracias estatais. Em Embedded Autonomy, Evans (1995) argumenta que a plena contribuição potencial das burocracias estatais para acumulação de capital é provável de ser realizada somente quando a coerência corporativa, fornecida pelas características weberianas, é combinada com denso conjunto sistemático de vínculos com a classe empreendedora. Em uma tendência diferente, teóricos da "Nova Administração Pública" destacariam mecanismos de "imitação de mercado" como "pagamento por desempenho" (ver Barzelay, 1997; Hood e Jackson, 1991; Milgrom e Roberts, 1992; Olsen e Peters, 1996).
} 
Se aceitarmos o argumento de que esses aspectos estruturais contribuem para uma burocracia mais competente, coesa e intencional, será plausível a existência de uma miríade de caminhos causais que levem a maiores taxas de crescimento econômico. Os horizontes temporais ampliados, associados a carreiras previsíveis e gratificantes, aumentaram a propensão da burocracia a advogar investimentos na infraestrutura do setor público, em vez de despesas com consumo. O retorno dos investimentos com infraestrutura do setor público depende essencialmente de sua "sistematicidade"; por isso, a coerência corporativa deveria melhorar sua eficácia. Da mesma forma, a redução das práticas de maximização individual (ou seja, corrupção) deveria, por sua vez, reduzir sobre o setor privado o imposto implícito que tal prática representa.

Relações difusas podem apresentar a mesma ou até superior importância. A maior parte da literatura de estudos de caso sobre "estados desenvolvimentistas" orienta-se, principalmente, para o papel das burocracias estatais em evocar taxas mais altas de investimento privado (p. ex., AMSDEN, 1989; EVANS, 1995; JoHnson, 1982; WADE, 1991; BANCO MUNDIAL, 1993). Obviamente, empreendedores racionais e avessos ao risco evitarão fazer investimentos de longo prazo em empresas e equipamentos, se eles se depararem com uma burocracia corrupta e imprevisível e que não ofereça investimentos públicos complementares. Pela mesma razão, percepções compartilhadas sobre burocracia estatal como confiável, previsível, minimamente competente e comprometida com o crescimento de longo prazo fazem com que os investimentos pareçam menos arriscados.

Burocracias competentes podem ajudar os empreendedores individuais a superar problemas de coordenação, o que pode vir a ser fundamental para que novas atividades sejam suscitadas. Elas também podem transformar recursos de informação em ativos públicos, de maneira a aumentar a probabilidade e eficácia de investimentos (ver RodRIK, 1995). Por exemplo, quando empresários em pequenos países estão tentando entrar no mercado mundial, ações coletivas para reunir informações sobre mercados externos e impor padrões entre os produtores locais podem conferir importantes vantagens. Burocracias respeitadas poderiam agir como "corretores honestos" na superação de problemas de ações coletivas entre os exportadores. Uma versão mais sólida desse argumento veria a própria burocracia reunindo e coletando informações, e fornecendo conselhos e incentivos que auxiliem firmas locais a melhor percorrer seu caminho no labirinto dos mercados mundiais que, a diário, sofrem mudanças ${ }^{11}$.

\footnotetext{
${ }^{11}$ Segundo Keesing (1988), esse é essencialmente o papel das burocracias que promovem o comércio nos quatro tigres asiáticos. Ver também Rodrik (1995).
} 
Escolher entre os vários caminhos que podem explicar a conexão entre a burocracia estatal coerente e o crescimento econômico competente seria uma tarefa desafiadora e interessante; contudo, esse não é o objetivo do presente trabalho. Pretende-se aqui estabelecer o vínculo básico entre estruturas burocráticas e crescimento econômico, fornecendo, portanto, incentivo adicional para a exploração de mecanismos alternativos que possam explicar semelhante conexão ${ }^{12}$.

Para reiterar tal propósito, avaliou-se o efeito de um conjunto particular de estruturas burocráticas; não procuramos realizar uma avaliação abrangente de todos os aspectos da estrutura burocrática passíveis de melhoria no concernente ao desempenho econômico. Foram selecionados o recrutamento meritocrático e a evolução de carreiras devido às fortes reivindicações desses aspectos na literatura e também porque eles constituem um conjunto de características estruturais, empiricamente identificáveis e teoricamente plausíveis, que oferecem um bom ponto de partida para a demonstração do valor de se fazer nova pesquisa sobre as consequências econômicas das variações nas estruturas burocráticas.

A estratégia utilizada para conectar estruturas burocráticas e crescimento econômico difere das de Weber. Weber estava interessado em mudanças históricas de longo prazo nas formas organizacionais. O presente trabalho se interessa por comparações intersecionais no período contemporâneo. A proposição empírica aqui feita é simples. Prevê-se que países cujas estruturas burocráticas incorporaram os aspectos weberianos terão experimentado mais crescimento econômico rápido nos 20 anos compreendidos entre os anos 1970 e 1990, do que aqueles em que tais aspectos não foram completamente adotados.

\footnotetext{
12 Existe outro conjunto de argumentos na literatura que postula um papel mais central para burocracias estatais na formação das trajetórias nacionais de investimentos e crescimento. Tais argumentos envolvem tanto as habilidades dos governos de estimular empresários a investir maiores quantias de seus lucros ao "discipliná-los" (cf. AMSDEN, 1989), quanto a habilidade das agências públicas de estimular formas de investimentos mais arriscadas, porém mais gratificantes por intermédio de subsídios seletivos e proteção contra concorrência externa (cf. Amsden, 1989; Ernst e O'ConNor, 1992;. Evans, 1995; WAde, 1990). Enquanto esses argumentos são plausíveis, eles claramente necessitam mais do que a mínima competência por parte da burocracia. Na medida em que esses argumentos são aplicados, o caso, pela importância de estruturas burocráticas, torna-se muito mais importante; contudo, a plausibilidade teórica da hipótese weberiana não depende desse argumento mais consolidado em relação ao papel das instituições públicas de fazer o crescimento possível.
} 


\section{Dados}

A ausência de medidas comparáveis de estruturas burocráticas para um conjunto substancial de países é um dos principais impedimentos para a avaliação dos efeitos da variação da burocracia sobre o crescimento econômico. Decidimos que somente pela coleta de dados recentes e originais seria possível ultrapassar tal obstáculo. O "conjunto de dados do Estado weberiano"13 que foi coletado é construído com base nas avaliações, passíveis de comparação, de especialistas sobre as estruturas burocráticas em 35 países, laboriosamente reunidas por um período de quase três anos (1993-1996).

A amostra começa com os 30 países "semi-industrializados" identificados por Chenery (1980) e foi complementada com cinco países mais pobres. Partimos da amostra de Chenery por três motivos. Para começar, estimou-se que os recursos disponíveis não permitiriam a coleta de dados para mais do que 35 países, então a amostra de Chenery tinha o tamanho certo. Em segundo lugar, havia o interesse de entender variações no crescimento entre países em desenvolvimento, em vez de entre países em desenvolvimento e países com indústria avançada. Ambicionou-se incluir países que ainda estavam enfrentando a questão da transformação industrial durante o período considerado. A amostra de Chenery forneceu uma variedade considerável de países em desenvolvimento. Em terceiro lugar, procurávamos suficiente diversidade de variações de "weberianismo". Mesmo não existindo dados sistemáticos disponíveis sobre o "weberianismo" per se, sabia-se que variações no "desempenho burocrático" eram muito mais abundantes entre países em desenvolvimento do que em países industrializados. Essa última consideração foi também um motivo para incluir alguns países pobres demais para terem sido considerados na amostra de Chenery. Dados sobre o desempenho burocrático mostraram que a exclusão de países mais pobres deixaria a amostra insuficiente para o espectro inferior da distribuição sobre desempenho burocrático e, portanto, poderia deixar também a amostra insuficiente para o baixo nível de weberianismo (ver Rauch e Evans, 1999, p. 8-9, Fig. 1b, 1c). A seleção dos países pobres a serem incluídos foi direcionada pelo desejo de aumento da representação do Caribe, do Sul da Ásia e da África subsaariana, e por acreditar que existiam especialistas sobre as burocracias desses países em número suficiente, para permitir que fossem encontrados pelo menos três deles para cada um dos países ${ }^{14}$. A amostra resultante dos 35 países representa as maiores

\footnotetext{
${ }^{13}$ A discussão do conjunto de dados weberianos é desenhada principalmente por Talbot (1997).

${ }^{14}$ Os cinco países adicionados à amostra de Chenery foram: Haiti, Nigéria, Paquistão, Sri Lanka e o Zaire (Congo). Para outras análises da amostra inicial de Chenery, ver Feder (1983) e Esfahani (1991).
} 
regiões do mundo em desenvolvimento e também da faixa sul da Europa da Organização para Cooperação e Desenvolvimento Econômico (OCDE). Ela também oferece uma variedade de desempenho de crescimento, durante os anos 1970 e 1980, da Coreia do Sul e de Cingapura (que cresceram consistentemente mais de $6 \%$ ao ano) até o Zaire (hoje Congo. N.T) (contraindo mais de $2 \%$ ). Ao mesmo tempo, a amostra dos países provê uma boa variedade em termos de "desempenhos burocráticos", como mensurado pelos serviços de classificação comercial (ver Rauch e Evans, 1999, p. 8-9, Fig. 1b e 1c).

Auferir medidas de diferentes aspectos da estrutura burocrática em cada um dos países demandou a cooperação de um grande número de especialistas, cada qual com conhecimento específico da burocracia estatal de um país em particular. Coletar as respostas foi laborioso, mas o nível de colaboração foi tão surpreendente quanto gratificante. Conseguimos, finalmente, reunir respostas de 126 especialistas, sendo que para 32 países foram acionados pelo menos três especialistas e, para os outros três países da amostra (Marrocos, Tailândia e Uruguai), foram acionados dois especialistas. Os especialistas foram escolhidos a partir de uma combinação de estudiosos conhecidos por suas pesquisas sobre a burocracia de cada país, agentes da burocracia local com reputação de ter uma ampla perspectiva da estrutura administrativa de seu país, e profissionais que trabalham com essa questão em organizações multilaterais. Juntos, os especialistas, na amostra do presente documento, representam uma porção substancial da literatura publicada sobre burocracias estatais para os países da amostra ${ }^{15}$.

As avaliações dos especialistas foram estruturadas por meio de um questionário com respostas fechadas ${ }^{16}$. Ao responder às questões com resposta fechada, foi pedido aos especialistas para, primeiramente, identificar as agências estatais centrais que tinham o papel mais importante na formulação de políticas econômicas, e depois responder às questões sobre elas ${ }^{17}$. Pensou-se que a estrutura das principais agências econômicas provavelmente exercia influência sobre o crescimento econômico. Além disso, porque os estudos de caso dos países mostraram que há usualmente variação substancial entre as agências, conseguir

\footnotetext{
${ }_{15}$ Para discussão mais detalhada da distribuição dos diferentes tipos de especialistas nos países, ver Talbot (1997, Tabela 2).

${ }^{16}$ Todos os especialistas foram encorajados a fornecer comentários e materiais adicionais, e a maioria assim o fez. Esse material adicional foi revisado durante a codificação das questões com resposta fixa, mas não foram analisados separadamente no presente documento.

${ }^{17}$ Especificamente, os especialistas foram solicitados a "listar as quatro principais agências na burocracia estatal central" na ordem de seu poder de modelar a política econômica geral.
} 
uma forma de mensuração que focasse nas agências mais importantes fazia sentido. Questões relevantes para a burocracia estatal geralmente acompanhavam aquelas focadas nas principais agências econômicas ${ }^{18}$.

Os especialistas nos países não foram instados a avaliar o desempenho ou a qualidade da burocracia. Em vez disso, o questionário focou-se em aspectos descritivos específicos da burocracia, que estão sujeitos à inferência objetiva. Esses aspectos descritivos foram, então, combinados para construir uma medida simples que refletisse a estrutura burocrática weberiana construída sobre o recrutamento meritocrático e evoluções de carreiras estruturadas com progressão funcional e gratificação de desempenho.

Devido ao fato de as estruturas burocráticas serem notoriamente resistentes às mudanças, ficamos seguros ao assumir que as diferenças descobertas entre as estruturas burocráticas caracterizariam a situação vigente no começo do período (e que provavelmente vigora desde antes dos anos 1970) e foram, portanto, temporariamente antecedentes ao crescimento durante o período dos anos 1970 a 1990. Para verificar essas suposições, os especialistas foram instados a não somente prover respostas que caracterizassem todo o período, como também observar qualquer mudança significativa durante o período. Apesar de algumas referências à deterioração na situação dos burocratas ao longo do tempo (particularmente em relação a salários relativos), ficou claro, em seus comentários, que as estruturas burocráticas descritas antecediam o crescimento econômico dos anos 1970 a $1990^{19}$.

Dez questões foram utilizadas para criar a chamada "Escala de Weberianismo" (ver Apêndice A para discussão sobre a escala e uma lista de itens). A questão inicial indica a importância das agências, em análise, na geração de políticas econômicas. Duas das questões subsequentes (questões 2 e 9 no Apêndice A) mediam a importância de exames para recrutar os funcionários públicos para as principais agências econômicas e para as demais ${ }^{20}$.

Três das questões abordam temas relacionados às carreiras: se funcionários públicos, uma vez recrutados, têm maior probabilidade de permanecer no serviço

\footnotetext{
${ }_{18}$ Para o questionário completo, ver Rauch e Evans (1999, Apêndice A). Para a codificação do questionário, ver Talbot (1997, Apêndice A).

19 Embora as estruturas burocráticas fossem geralmente estáveis durante o período estudado, os comentários dos especialistas indicaram que o começo dos anos 1990 pode ter sido um período de mudança, no qual variadas burocracias foram reestruturadas devido à pressão de agências multilaterais.

${ }^{20}$ A questão 9 é, na verdade, uma composição criada pela combinação das respostas às questões 17 e 18 do questionário original.
} 
público (questões 3 e 5) e se ficar no serviço público implica possibilidades de subir na hierarquia (questão 4). Quatro questões adicionais tratavam de gratificações de carreira, tanto em termos de salários, como em prestígio (questões 6, 7, 8 e 10). A Escala de Weberianismo resultante fornece uma medida sucinta e substancialmente plausível dos aspectos burocráticos, que são o foco da pesquisa.

Para descobrir que relação, se houver alguma, pode existir entre esses aspectos e o crescimento econômico dos anos 1970 a 1990, baseamo-nos em medidas de conjuntos de dados padronizados disponíveis para criar a variável dependente do estudo, crescimento em PIB per capita de 1970 a 1990, e as variáveis de controle, nível de renda inicial e capital humano preexistente. (Ver Apêndice B para definições e fonte dos dados para as variáveis de controle e dependente). A versão de 1994 ("Mark 5.5") da Penn World Tables de Summers e Heston (1991) forneceu a fonte para a mensuração do PIB real per capita nos anos 1965, 1970 e 1990. Como indicador para o capital humano, utilizou-se uma versão atualizada da medida da média de anos de frequência à escola para a população com 25 anos ou mais, de Barro e Lee (1993).

\section{Análise}

O objetivo do presente estudo é descobrir se o "weberianismo" tem efeito sobre o crescimento econômico, que é independente dos efeitos de outras variáveis classicamente associadas ao desenvolvimento econômico. Existe uma forte e significativa correlação entre a pontuação na Escala de Weberianismo e o crescimento total do PIB real per capita durante o período de 1970 a 1990 ( $r=67 ; p$ $<.001)$, mas pode-se argumentar que o weberianismo é simplesmente um indicador para o nível geral de desenvolvimento ou estoques existentes de capital humano (ver Apêndice $C$ para a Escala de Weberianismo para os 35 países da amostra). Tal argumento não pode ser descartado. Sabe-se que burocracias mais bem desenvolvidas são mais prováveis de serem encontradas entre os países desenvolvidos (RAuch e Evans, 1998, p. 8, Fig. 1a; ver também Banco Mundial, 1997). Sabe-se também que altos níveis de capital humano, que são geralmente associados a altos níveis de desenvolvimento, estão fortemente associados ao crescimento. Na verdade, praticamente nenhuma associação foi observada entre o grau de aproximação das características weberianas e os níveis iniciais de renda per capita nessa amostra de países em desenvolvimento $(r=.05)$. Pelo menos na presente amostra de países em desenvolvimento, parece difícil argumentar que crescimento prévio ou maiores níveis de renda são causas importantes, por si sós, de Estados mais weberianos. De maneira mais otimista, parece que baixos níveis de renda per capita não são necessariamente uma barreira para que burocracias 
estatais competentes e coerentes sejam alcançadas. Entretanto, existe uma modesta (contudo não significativa) correlação entre a Escala de Weberianismo da presente amostra e um preexistente nível de capital humano $(r \approx .25, p=.15)$ e, por sua vez, o capital humano tem um efeito positivo significativo sobre o crescimento subsequente.

Assim, o primeiro resultado-chave consiste em que, mesmo após os efeitos dos níveis iniciais do PIB per capita e os níveis preexistentes de capital humano terem sido controlados, a relação entre a pontuação na Escala de Weberianismo e o crescimento econômico continua forte e significativa. Como a regressão abaixo indica, a Escala de Weberianismo continua a ter um poderoso e significativo impacto sobre o crescimento econômico. O Weberianismo não é apenas um indicador espúrio para efeitos dos níveis preexistentes de desenvolvimento ou de capital humano.

A equação básica em forma não padronizada é:

\% Mudança no PIB per capita 1970-1990=

-44.54 - .02 (PIB real per capita 1965)

+15.77 (média de anos de estudo 1965)

+16.05 (pontuação weberianismo).

Em forma padrão, a equação se apresenta assim:

$\%$ Mudança do PIB per capita 1970-1990 =

-3.17 (PIB real per capita 1965)

+.307 (média de anos de estudo)

+.615 (pontuação weberianismo)

Na Figura 1, mostra-se o gráfico de dispersão do crescimento regredido sobre a Escala de Weberianismo com os efeitos do nível inicial do PIB per capita e do nível preexistente de capital humano controlados. Uma das questões que sobressai nesse gráfico de dispersão é o acentuado grau no qual a distribuição regional das características weberianas se emparelha com as diferenças regionais de desempenho do crescimento.

Diferenças regionais em ambos os crescimentos, no PIB e no weberianismo, estão resumidas nas Figuras 2 e 3 . A Figura 2 mostra a amplitude total, a amplitude interquartílica e a mediana para o crescimento do PIB em cada um dos quatro grupos regionais dos países. Quando as quatro regiões são dispostas na ordem que seria esperada, baseando-se na literatura existente, elas quase formam uma perfeita linha de regressão, tendo a África subsaariana em sua base e os quatro 
Escala de Weberianismo (Pontuação bruta)

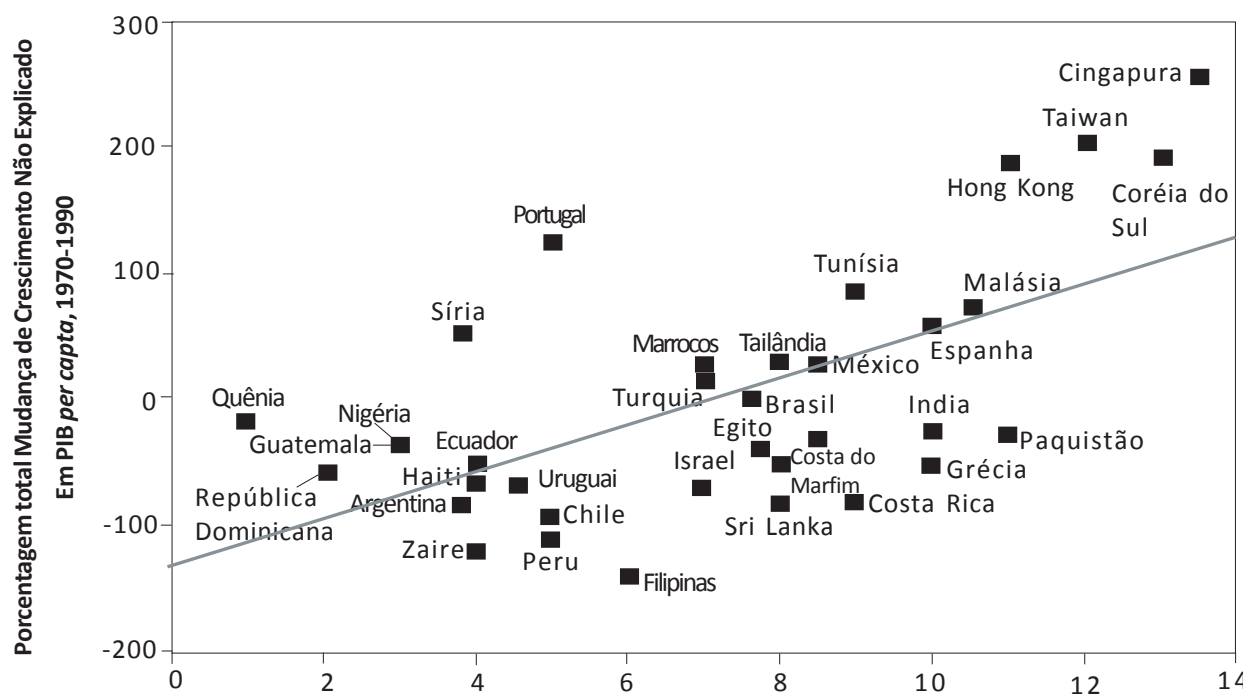

Nota: Crescimento não explicado é o crescimento não explicado pelo nível do PIB em 1965 e os anos de escola em 1965.

Figura 1: Gráfico de dispersão mostrando a relação entre a pontuação na Escala de Weberianismo e o crescimento não explicado do PIB per capita, 1970 a 1990

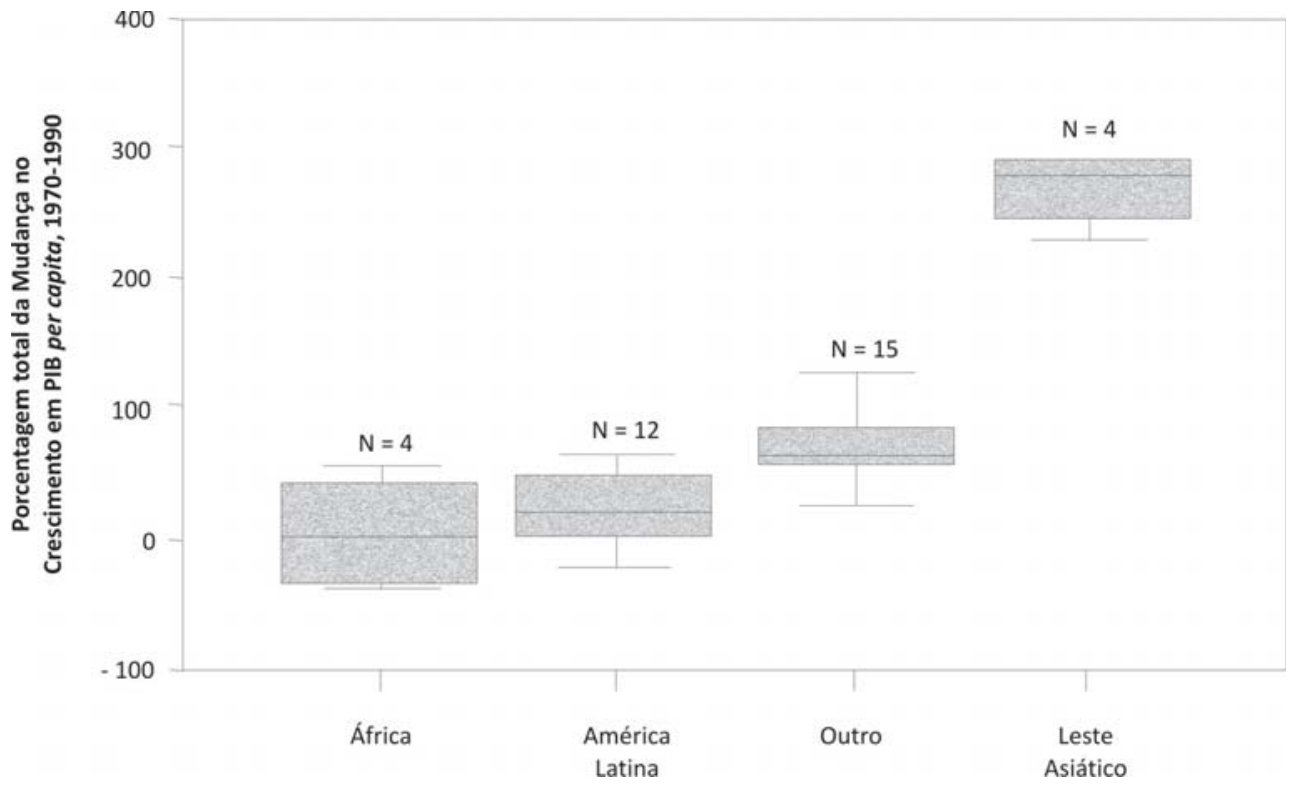

Figura 2: Boxplot do crescimento em PIB per capita por região, 1970 a 1990. 
Tigres Asiáticos no topo. A região da América Latina exibe um desempenho de crescimento que é claramente inferior a qualquer região, menos à da África subsaariana, principalmente porque o crescimento que a América Latina experimentou, no período que está sendo examinado, é denominado de "década perdida" dos anos 1980.

A Figura 3 retrata as diferenças regionais na Escala de Weberianismo e traça um paralelo claro entre as variações regionais no crescimento e as variações regionais das estruturas burocráticas. Assim como a África subsaariana delineia a parte baixa da escala em termos de crescimento, ela também é a região na qual os Estados são menos weberianos. Da mesma maneira, os quatro Tigres Asiáticos personificam, pelo menos durante esse período, tanto o alto crescimento quanto traços marcados de burocracia weberiana. A Escala de Weberianismo parece capturar o elemento institucional fundamental das economias do Leste Asiático de "alto desempenho", enquanto aponta para um déficit institucional que pode ajudar a explicar as baixas taxas de crescimento na África.

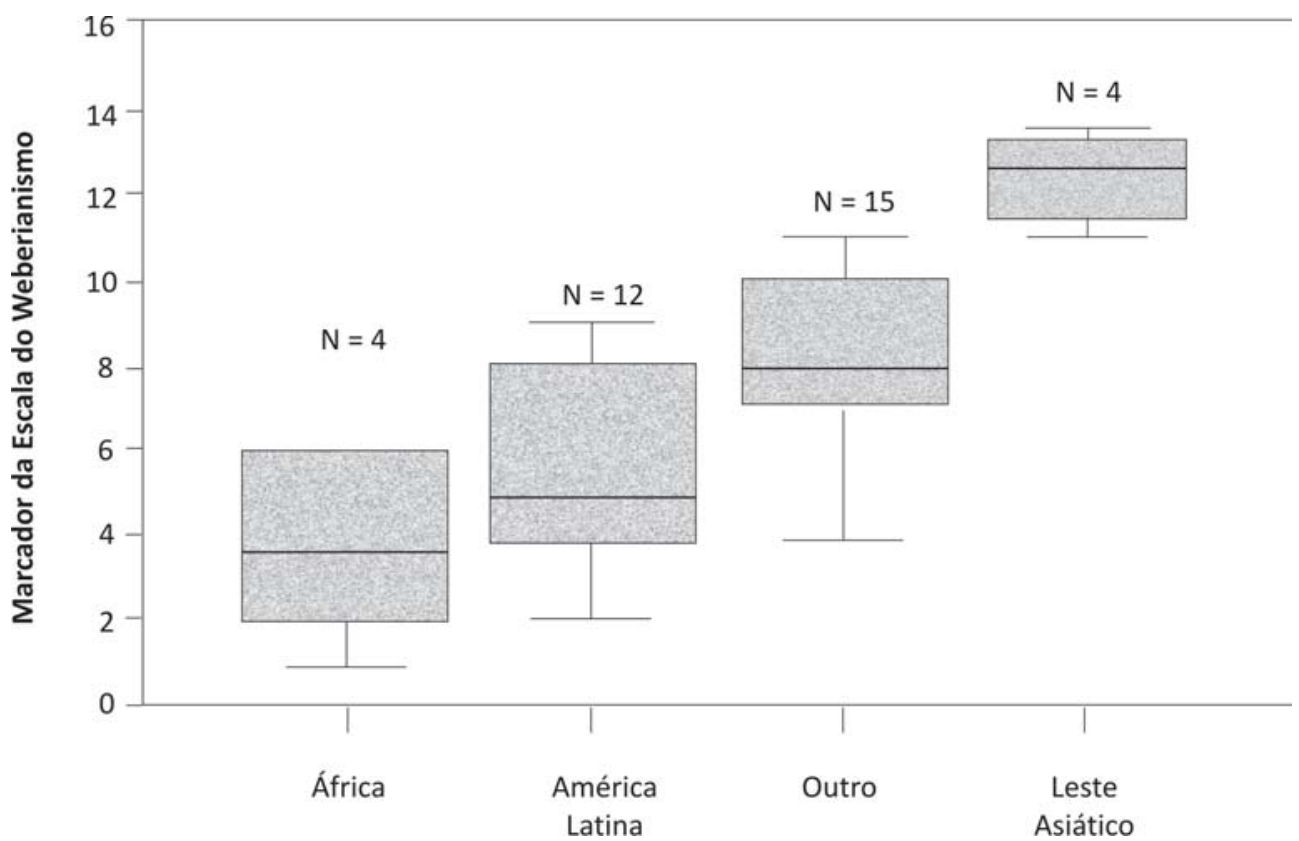

Figura 3: Boxplot da pontuação na Escala de Weberianismo por região 
Tabela 1: Coeficientes Padronizados de Regressão do Crescimento em PIB Real Per Capita, 1970-1990, em Selecionadas Variáveis Independentes: 35 Países em Desenvolvimento

\begin{tabular}{lrrrr}
\hline Variável Independente & Modelo 1 & Modelo 2 & Modelo 3 & Modelo 4 \\
\hline Pontuação na Escala de & $.615^{* *}$ & $.537^{* *}$ & $.599^{* *}$ & $.247^{*}$ \\
Weberianismo & $(4.649)$ & $(3.700)$ & $(4.268)$ & $(2.418)$ \\
PIB per capita, 1965 & -3.17 & -2.70 & -3.24 & -1.5 \\
Anos na escola, 1965 & $(-1.749)$ & $(-1.472)$ & $(-1.753)$ & $(-1.251)$ \\
América Latina & .307 & .319 & .290 & .090 \\
Affrica & $(1.645)$ & $(1.725)$ & $(1.487)$ & $(.724)$ \\
& -.180 & - & - & - \\
Leste Asiático & - & $-1.242)$ & -.056 & - \\
Número de países & - & - & $(-.367)$ & $.696^{* *}$ \\
Ajustado $R^{2}$ & - & - & - & $(6.638)$ \\
\hline
\end{tabular}

Nota: Números entre parênteses são valores $-t$.

$* p<.05 \quad * p<.01$ (teste bicaudal)

A Tabela 1 apresenta um conjunto de regressões que adiciona variáveis dummy por região para a regressão básica ilustrada na Figura 1. Os efeitos da Escala de Weberianismo ainda permanecem sólidos. Introduzir variáveis dummy para a África subsaariana e a América Latina provoca apenas uma redução modesta do coeficiente da Escala de Weberianismo (modelos 2 e 3). Mais importante ainda, um significativo "efeito de estrutura burocrática" permanece, mesmo quando a variável dummy para o Leste Asiático (os quatro Tigres) é incluída (modelo 4) ${ }^{21}$.

Será que os efeitos do weberianismo continuam a ser significantes em regressões que introduzem outras variáveis utilizadas em modelos padrões de crescimento? Levine e Renelt (1992) pesquisaram 41 estudos que utilizam regressões internacionais para explicar o crescimento econômico. Eles concluíram que, mesmo que "mais de 50 variáveis sejam significantemente correlacionadas

\footnotetext{
${ }^{21}$ Os efeitos da Escala de Weberianismo são robustos em face das diferentes definições de variáveis fictícias regionais (duas variações da variável fictícia do Leste Asiático que incluem seis ou sete países asiáticos) e uma versão mais ampla da variável africana (que inclui três países do norte africano). Na verdade, a Escala de Weberianismo tem um efeito mais poderoso quando a definição de "Leste Asiático" é utilizada. Somente quando a variável fictícia do Leste da Ásia é incluída, juntamente com as variáveis fictícias da África subsaariana ou da América Latina, é que o efeito da Escala do Weberianismo cai abaixo da significância estatística. Além disso, o efeito do weberianismo não é robusto em face da inclusão simultânea de três variáveis fictícias; mas, como essas variáveis incluem, em combinação, pelo menos 18 dos 35 países, esse é um teste extremamente restritivo.
} 
com crescimento em pelo menos uma regressão" (p. 924), a lista de variáveis cujos efeitos são verdadeiramente robustos é, na verdade, bem pequena. Eles identificaram três variáveis básicas - nível inicial de PIB per capita, investimentos e capital humano - como as mais robustamente relacionadas ao crescimento (1992, p. 947, Tabela 1). 0 modelo 5, na Tabela 2, mostra os resultados em relação a essas variáveis usando a amostra e o período do presente estudo, e as definições das variáveis condizem com o trabalho prévio, exceto que os efeitos do capital humano (anos de estudo) perdem importância (utilizando teste bicaudal). O investimento inicial é o mais significativo instrumento de predição de crescimento, e o nível inicial do PIB per capita continua a ter relação negativa com o crescimento.

Quando a Escala de Weberianismo é adicionada a essa equação elementar (modelo 7), ela se torna o mais poderoso instrumento de predição do crescimento e o $R^{2}$ ajustado aumenta significativamente. O modelo 6, na Tabela 2, mostra os efeitos de duas variáveis adicionais que Barro (1991) descobriu ter importante efeito negativo sobre crescimento - consumo do governo e revoluções. No modelo 6, quando essas variáveis são adicionadas ao conjunto básico de Levine e Renelt (modelo 5), seus coeficientes não são significativos, e eles resultam em apenas um aumento trivial do $\mathrm{R}^{2}$ ajustado ${ }^{22}$. No modelo 8 , a Escala de Weberianismo é adicionada ao modelo 6. Os resultados estão paralelos àqueles do modelo 7: a Escala de Weberianismo mais uma vez se torna o instrumento de predição mais significativo, e o $R^{2}$ ajustado é outra vez significativamente aumentado ${ }^{23}$. Em geral, esses resultados sugerem que, se os dados pudessem ser coletados para um maior alcance de países, o weberianismo se tornaria uma valiosa adição à literatura existente sobre modelos de crescimento internacionais.

\footnotetext{
22 Consistente com Barro (1991), o coeficiente para consumo do governo é negativo. Mas nos presentes resultados, somente é significativo ao nível $p<.10$. O consumo do governo tem uma considerável relação negativa com o crescimento quando o investimento é omitido das regressões (por exemplo, quando somente o nível inicial do PIB e o capital humano são incluídos). O coeficiente para a variável de revoluções sempre é insignificante (contudo, consistentemente negativo).

${ }^{23}$ Podíamos esperar que houvesse uma relação de interação entre consumo do governo, a pontuação da Escala de Weberianismo e crescimento, tal que o aumento do weberianismo reduziria ou reverteria o efeito negativo do consumo governamental sobre o crescimento. Tentou-se introduzir um termo de interação (Escala de Weberianismo x consumo governamental) em diferentes regressões; porém, não se encontrou nenhum efeito expressivo. No entanto, vale ressaltar que existe uma forte correlação negativa entre weberianismo e consumo governamental na presente amostra $(r=-.35 ; p<.05)$, o que é consistente com as observações da literatura de estudos de caso, de que os Estados em desenvolvimento não são usualmente "grandes" Estados em termos fiscais.
} 
Tabela 2: Coeficientes Padronizados de Regressão do Crescimento em PIB Per Capita Real, 1970-1990 em Variáveis Independentes Selecionadas: 35 Países em Desenvolvimento

\begin{tabular}{|c|c|c|c|c|}
\hline Variável Independente & Modelo 5 & Modelo 6 & Modelo 7 & Modelo 8 \\
\hline $\begin{array}{l}\text { Pontuação na Escala de } \\
\text { Weberianismo }\end{array}$ & - & - & $\begin{array}{l}.490^{* *} \\
(3.647)\end{array}$ & $\begin{array}{r}.482 * * \\
(3.104)\end{array}$ \\
\hline PIB per capita, 1965 & $\begin{array}{l}-.644^{* *} \\
(-3.171)\end{array}$ & $\begin{array}{l}-.778^{* *} \\
(-3.642)\end{array}$ & $\begin{array}{r}-.458^{*} \\
(-2.554)\end{array}$ & $\begin{array}{r}-.498^{*} \\
(-2.402)\end{array}$ \\
\hline Anos de estudo, 1965 & $\begin{array}{r}.401 \\
(1988)\end{array}$ & $\begin{array}{r}.420^{*} \\
(2.068)\end{array}$ & $\begin{array}{r}.258 \\
(1,470)\end{array}$ & $\begin{array}{r}.211 \\
(1.115)\end{array}$ \\
\hline $\begin{array}{l}\text { Proporção média anual do } \\
\text { investimento doméstico } \\
\text { 1965-1970 }\end{array}$ & $\begin{array}{l}.580 * * \\
(3.498)\end{array}$ & $\begin{array}{r}.434^{*} \\
(2.463)\end{array}$ & $\begin{array}{r}.360^{*} \\
(2.362)\end{array}$ & $\begin{array}{r}.298 \\
(1.861)\end{array}$ \\
\hline $\begin{array}{l}\text { Proporção média anual } \\
\text { das despesas do governo } \\
\text { com consumo, 1970-1985 }\end{array}$ & - & $\begin{array}{r}-.334 \\
(-2.024)\end{array}$ & - & $\begin{array}{r}-.179 \\
(-1.169)\end{array}$ \\
\hline $\begin{array}{l}\text { Revoluções-média por ano, } \\
\text { 1970-1985 }\end{array}$ & - & $\begin{array}{r}-.136 \\
(-.950)\end{array}$ & - & $\begin{array}{r}-.003 \\
(-.023)\end{array}$ \\
\hline Número de países & 35 & $34 a$ & 35 & $34 \mathrm{a}$ \\
\hline $\mathrm{R}^{2}$ ajustado & .343 & .373 & .529 & .521 \\
\hline
\end{tabular}

Nota: Números entre parênteses são valores $-t$.

a Costa do Marfim não tem dados sobre consumo do governo, e, portanto, é omitido.

${ }^{*} \mathrm{p}<.05 \quad * * \mathrm{p}<.01$ (testes bicaudais)

Dada a poderosa e robusta relação entre níveis de investimento e crescimento na literatura internacional-padrão e o fato de que o trabalho sociológico em modelos internacionais de crescimento também enfatiza a importância do papel do investimento (cf. Firebaugh, 1992, p. 125), faz sentido analisar os efeitos do weberianismo tanto sobre os níveis de investimento, como também sobre as taxas de crescimento $^{24}$. A Tabela 3 mostra que a pontuação na Escala de Weberianismo tem um efeito positivo constante e significativo sobre os níveis finais de investimentos no período, reforçando a posição geralmente aceita na literatura dos estudos de caso sobre "Estados em desenvolvimento", o que enfatiza o papel do Estado na elevação dos níveis de investimento privado, como principal mecanismo pelo qual estados podem promover maiores taxas de crescimento (Evans, 1995) ${ }^{25}$.

\footnotetext{
${ }^{24}$ Assim como Firebaugh, Barro (1991, p. 426, Tabela III) também reportou resultados utilizando investimentos como uma variável dependente. Ele não utilizou, contudo, investimentos como uma variável explicadora em suas "básicas" regressões de crescimento (BARro, 1991, p. 410, Tabela I), presumidamente por causa da preocupação com a endogeneidade. Tentou-se evitá-la ao utilizar-se somente o nível anterior de investimento nas regressões de crescimento do presente documento.

${ }^{25}$ Também foi explorada a relação entre weberianismo e os níveis de investimento público, com o pensamento de que introduzir um termo de intenção pode revelar um significativo efeito positivo do investimento público sobre o crescimento ligado aos altos níveis de weberianismo. Não foi encontrado tal efeito.
} 
Tabela 3: Coeficientes Padronizados de Regressão do Crescimento em PIB Per Capita Real, 1970-1990 em Variáveis Independentes Selecionadas: 35 Países em Desenvolvimento

\begin{tabular}{|c|c|c|c|c|c|}
\hline Variável Independente & Modelo 09 & Modelo 10 & $\begin{array}{r}\text { Modelo } \\
11 \\
\end{array}$ & $\begin{array}{r}\text { Modelo } \\
12\end{array}$ & $\begin{array}{r}\text { Modelo } \\
13 \\
\end{array}$ \\
\hline $\begin{array}{l}\text { Pontuação na Escala de } \\
\text { Weberianismo }\end{array}$ & $\begin{array}{l}.489^{* *} \\
(3.508)\end{array}$ & $\begin{array}{l}.477^{* *} \\
(3.044)\end{array}$ & $\begin{array}{l}.456 * * \\
(3.103)\end{array}$ & $\begin{array}{r}.348^{*} \\
(2.146)\end{array}$ & $\begin{array}{r}.370^{*} \\
(2.276)\end{array}$ \\
\hline PIB per capita, 1965 & $\begin{array}{r}-.179 \\
(-.936)\end{array}$ & $\begin{array}{r}-.172 \\
(-.867)\end{array}$ & $\begin{array}{r}-.194 \\
(-1.003)\end{array}$ & $\begin{array}{r}-.115 \\
(-.603)\end{array}$ & $\begin{array}{r}-.354 \\
(-1.609)\end{array}$ \\
\hline Anos de estudo, 1965 & $\begin{array}{r}.443 * \\
(2.255)\end{array}$ & $\begin{array}{r}.445^{*} \\
(2.225)\end{array}$ & $\begin{array}{r}.407 \\
(1.994)\end{array}$ & $\begin{array}{r}.360 \\
(1.814)\end{array}$ & $\begin{array}{r}.436 \mathrm{a} \\
(2.128)\end{array}$ \\
\hline $\begin{array}{l}\text { Proporção média anual } \\
\text { das despesas do } \\
\text { governo com } \\
\text { consumo, 1970-1985 }\end{array}$ & - & - & - & - & $\begin{array}{r}-.314 \\
(-1.931)\end{array}$ \\
\hline $\begin{array}{l}\text { Revoluções por ano em } \\
\text { média, 1970-1985 }\end{array}$ & - & - & - & - & $\begin{array}{r}-1.36 \\
(-.951)\end{array}$ \\
\hline América Latina & - & $\begin{array}{r}-.026 \\
(-.169)\end{array}$ & - & - & - \\
\hline África & - & - & $\begin{array}{r}-.119 \\
(-.747)\end{array}$ & - & - \\
\hline Leste Asiático & - & - & - & $\begin{array}{r}.267 \\
(1.599)\end{array}$ & - \\
\hline Número de países & 35 & 35 & 35 & 35 & $34 \mathrm{a}$ \\
\hline$R^{2}$ ajustado & .400 & .381 & .392 & .429 & .434 \\
\hline
\end{tabular}

\section{Discussão}

A evidência aqui apresentada reforça a proposição de que as burocracias estatais caracterizadas pelo recrutamento meritocrático e por carreiras previsíveis e gratificantes estão associadas a maiores taxas de crescimento. Devido ao fato de os dados se referirem principalmente às principais agências econômicas, a conclusão não é a de que todo o aparato burocrático deva ser estruturado dessa maneira para ter efeitos positivos sobre o crescimento. Ter estruturas weberianas no centro estratégico da burocracia pode ser o suficiente.

O weberianismo oferece um relato detalhado e analiticamente satisfatório sobre as diferenças observadas no desempenho regional do crescimento. Esses resultados apoiam as interpretações do elevado crescimento do Leste Asiático que enfatizam a contribuição da burocracia competente e coerente e oferecem uma alternativa sucinta e objetiva para a ideia não satisfatória, antiteórica e amorfa de um "efeito do Leste Asiático". Os resultados também são consistentes com as explicações sobre as baixas taxas de crescimento africano, que enfatizam os problemas de governança. 
Em geral, esses resultados sugerem que uma importante contribuição poderia ser feita à literatura existente sobre a análise internacional do crescimento se evidências sistemáticas fossem reunidas, servindo-se de uma grande amostra de países. Weberianismo é uma contribuição sociológica potencial ao pequeno conjunto de sólidos indicadores do crescimento, que foram identificados por economistas em recentes estudos internacionais.

Apesar do caráter promissor dos resultados aqui apresentados, ressalta-se que esta pesquisa é somente o começo. Sem dúvida, existem diversos caminhos para a continuação deste trabalho. Reunir os dados sobre estruturas burocráticas para uma ampla amostra de países é o primeiro passo em direção a um melhor teste de robustez das relações aqui encontradas ${ }^{26}$. O sucesso do esforço inicial aqui reportado argumenta que os retornos, oriundos do levantamento de mais e melhores evidências sobre variações internacionais das características estruturais da burocracia estatal, mais do que justificariam o esforço necessário para tal.

Um objetivo mais ambicioso consiste em estender o período temporal da coleta de dados de acordo com as mudanças no caráter das burocracias públicas durante os anos 1990. Essa tarefa é relevante para a compreensão das origens dos problemas econômicos atuais no Leste da Ásia. Estudos de caso anteriores enfatizaram que pode ser difícil sustentar o caráter weberiano das burocracias do Leste Asiático (AMSDEN, 1989; EvANS, 1995). Análises recentes sugeriram que a integridade decrescente das burocracias públicas teve um papel importante na deterioração do sistema financeiro do Leste Asiático (p. ex., CHAN, PARK e Yoo, 1998).

Finalmente, seria esclarecedor examinar a relação entre weberianismo e uma gama de outras variáveis políticas, econômicas e sociais que estão relacionadas com o crescimento. Regimes políticos (Alvarez, et al., 1996) e a produção de políticas comumente utilizadas em regressões internacionais (p. ex., ágio no mercado negro, superávit fiscal, distorção de preços) são dois exemplos ${ }^{27}$.

Embora ainda tenha muito a ser feito, uma conclusão incontroversa transcende o caráter exploratório do nosso estudo: a "hipótese do estado weberiano" merece mais atenção dos sociólogos e outros cientistas sociais, tanto de maneira empírica quanto analítica.

\footnotetext{
${ }^{26}$ Um projeto está atualmente nos estágios de planejamento na United Nations University, que estenderia a cobertura de dados para mais 15 ou 20 países da África subsaariana. Até o presente momento, entretanto, a maior parte dos esforços de promoção do interesse das agências de financiamento para apoiar a construção da infraestrutura de dados necessária teve resultados desalentadores.

${ }^{27}$ Em outro estudo (Rauch e Evans, em breve), examina-se a relação entre weberianismo e as variáveis de desempenho burocrático comumente utilizadas.
} 


\section{Referências bibliográficas}

Alvarez; Mike; Cheibub, José Antonio; Limongl, Fernando; Przeworski. Classifying Political Regimes. In: Studies in Comparative International Development. Georgetwon University, v. 31, n. 2, p. 3-36, 1996.

Amsden, Alice. Asia's Next Giant: South Korea and Late Industrialization. New York: Osford University Press, 1989.

Banco Mundial. The East Asian Miracle: Economic Growth and Public Policy. A World Bank Policy Research Report. New York: Oxford University Press, 1993.

Adjustment in Africa: Reforms, Results and the Road Ahead. New York: Oxford University Press, 1994.

World Development Report: The State in a Changing World. New York: Oxford University Press, 1997.

Banco Mundial; Keesing, Donald B. The Four Successful Exceptions: Official Export Promotion and Support for Marketing in Korea, Hong Kong, Singapore, and Taiwan, China. Occasional Paper \#2, UNDP-World Bank Trade Expansion Program, Washington, DC, 1988.

BARRo, Robert J. Economic Growth in a Cross-Section of Countries. Quarterly Journal of Economics, v. 106, p. 407-444, 1991.

BARro, Robert J.; LeE, Jong-wha. International Comparisons of Educational Attainment. Journal of Monetary Economics, v. 32, p. 363-394, 1993.

Barzelay, Michael. Results Oriented Government: Theories and Research on the New Public Management. Apresentado em: Aaron Wildvasky Forum For Public Policy. University of California, Berkley, Califórnia. 3-4 de Abril, 1997.

Bates, Robert H. Markets and States in Tropical Africa: The Political Basis of Agricultural Policies. Berkley, CA: University of California Press. 1981.

Bates, Robert H. Beyond the Miracle of the Market: The institutional Foundations of Agrarian Development in Kenya. Cambrige, England: Combridge University Press, 1989.

Buchanan, James M.; Tolisson, Robert D.; Tullock, Gordon. Toward a Theory of the Rent-Seeking Society. College Station, TX: Texas A\&M University Press. 1980.

Campos, Jose Egardo; Root, Hilton. The Key to the Asian Miracle: Making Shared Growth Credible. Washington, DC: Brooking Institution. 1996.

Callaghy, Thomas. Lost between State and Market: The Politics of Economic Adjustment in Gambia, Zambia and Nigeria. In: Economic Crisis and Policy: The Politics of Economic Adjustment in the Third World. Princeton, NJ: Princeton University Press.1989.

Chang, Ha-Joon; PARK, Hong Jae; YOO, Chul Gyue. Interpreting the Korean Crisis: Financial Liberalization, Industrial Policy, and Corporate Governance. Faculty of Economics and Politics, Cambridge University, Cambridge, England. 1998. Manuscrito não publicado. 
Cheng, Tun-jen; Haggard, Stephan; Kang, David. Institutions, Economic Policy and Growth in Korea and Taiwan. Apresentado em: UNCTAD Seminar on Development of East and South-East Asia and a New Development Strategy - The Role of Government. 30-31 de Outubro, Genebra, Suíça. 1995.

Chenery, Hollis B. World Bank. The Semi-industrialized Countries. Washington, DC. 1980. Manuscrito não publicado.

Colclough, Christopher; Manor, James. Markets: Neo-Liberalism and the Development Policy Debate. Oxford, England: Carendon, 1991.

Crowley, Angela; Rauch, James; Seagrave, Susanne; Smith, David. Quantitative CrossNational Studies of Economic Development: A Comparison of the Economics and Sociology Literatures. Studies in Comparative International Development, v. 33, n. 2, p. 30-57.

DelacroIx, Jacques; Ragin, Charles. Structural Blockage: A Cross-national Study of Economic Dependency, State Efficacy, and Underdevelopment. American Journal of Sociology, v. 86, p. 1311-1347, 1982.

EAsterly, William; LeVIne, Ross. Africa's Growth Tragedy: Policies and Ethnic Divisions. Quaterly Journal of Economics, v. 112, p. 1203-1250, 1997.

OECD; ERnst, Dieter; O'Connor, David. Competing in the Electronics Industry: The Experience of Newly Industrializing Countries. An OECD Development Centre Study, Paris, 1992.

HAIDI, Esfahani S. Exports, Imports, and Economic Growth in Semi-Industrializes Countries. Journal of Development Economics, v. 35, p. 93-116, 1991.

Evans, Peter. Embedded Autonomy: States and Industrial Transformation. Princeton, NJ: Princeton University Press, 1995.

FEDER, Gershon. On Exports and Economic Growth. Journal of Development Economics, v.12, n. 1-2, p. 59-73, 1983.

Firebaugh, Glenn. Growth Effects of Foreign and Domestic Investment. American Journal of Sociology, v. 98, p. 105-130, 1992.

GerTh, Hans; Mills, C.W. From Max Weber: Essays in Sociology. New York: Oxford University Press, 1958.

Hood, Christopher; JACKSON, Michael. Administrative Argument. Hanover, Adershot, England: Dartmouth, 1991.

Johnson, Chalmers. MITI and the Japonese Miracle: The Growth of Industrial Policy, 1925-1975. Standford, CA: Standford University Press, 1982.

KLITGARD, Robert. Controlling Corruption. Berkeley, CA: University of California Press, 1988.

Knack, Stephan; Keefer, Philip. Institutions and Economic Performance: CrossCountry Tests Using Alternative Institutional Measures. Economics and Politcs, v. 7, n. 3, p.207-227, 1995.

$\mathrm{KoH}$, Gillian. A Sociological Analysis of the Singapore Administrative Elite: The Bureaucracy in an Evolving Developmentalist State. 1995, Dissertação (PhD em Estudos Sociológicos), University of Sheffield, Sheffield, England. 
Krueger, Anne O. The Political Economy of the Rent-Seeking Society. American Economic Review, v. 64, p. 291-303.

La Porta, Rafael; Lopez-de-SILANes, Florencio; Shleifer, Andrei; Vishny, Robert. The Quality of Government. Journal of Law, Economics and Organization, v. 15, n. 1, p. 222-279, 1999.

Levine, Ross; Renelt, David. A Sensitivity Analysis of Cross-Country Growth Regressions. American Economic Review, v. 82, p. 942-963, 1992.

Robert, Lucas. On the Mechanics of Economic Development. Journal of Monetary Economics, v. 22, n. 1, p. 3-42.

MaUro, Paolo. Corruption and Growth. Quarterly Journal of Economics, v. 110, p. 681-712, 1995.

Milgrom, Paul; Roberts, John. Economics, Organization, and Management. Englewood Cliffs, NJ: Prentice Hall, 1992.

Nehru, Vikram; Swanson, Eric; Dubey, Ashutosh. A New Database on Human Capital Stock in Developing and Industrial Countries: Sources, Methodology, and Results. Journal of Development Economics, v. 46, p. 379-401, 1995.

Olsen, Johan, P.; Peters, B. Guy (eds). Lessons from Expirience: Experimental Learning in Administrative Reforms in Eight Democracies. Oxford, England: Scandinavian University Press, 1996.

Parsons, Talcott. Max Weber: The Theory of Economic and Social Organization. New York: Free Press, 1964.

Polanyl, Karl. The Great Transformation. Boston, MA: Beacon Press, [1944] 1957.

QuAH, Jonathan. The Rediscovery of the Market and Public Administration: Some Lessons from the Singapore Experience. Australian Journal of Public Administration, v. 52, p. 320-328, 1993.

Rauch, James; Evans, Peter. Bureaucratic Structure and Bureaucratic Performance in Less Developed Countries. Discussion Paper n. 99-06, Department of Economics, University of California, San Diego, CA, 1999.

Bureaucratic Structure and Bureaucratic Performand in Less Developed Countries. Journal of Public Economics.

RodRIK, Dani. Getting Interventions Right: How South Korea and Taiwan Grew Rich. Economic Policy, abril, v. 20, p. 55-97, 1995.

Romer, Paul. Increasing Return and Long Run Growth. Journal of Political Economy, v.94, n.5, p. 1002-1037, 1986.

Endogenous Technological Change. Journal of Political Economy, outubro, v. 90, n. 5, p. 71-102, 1990.

. The Origins of Endogenous Growth. Journal of Economic Perspectives, v. 8, n. 1, p. 3-22, 1994.

RuBInson, Richard. Dependence, Government Revenue and Economic Growth, 19651970. Studies in Comparative International Development, v. 12, p. 3-28, 1977. 
SnYDER, David; KıCK, Edward. Structural Position in the World System and Economic Growth, 1955-1970: A Multiple-Network Analysis of Transnational Interactions. American Journal of Sociology, v. 84, p. 1096-1126, 1979.

Stepan, Alfred. The State and Society: Peru in Comparative Perspective. Princeton, NJ: Princeton University Press, 1978.

Stinchсномве, Arthur. Creating Efficient Industrial Administrations. New York: Academic Press, 1974.

Summer, Roberts; Heston, Alan. The Penn World Table (Mark 5): AN Expanded Set of International Comparisons, 1950-1988. Quarterly Journal of Economics, v. 106, n. 2, p. 327-368, 1991. Versão atualizada 5.5 disponível em: http://www.nber.org, em: 1994.

TAlвot, John. A Description of the 'Weberian State' Comparative Data Set. Project Document, Bureaucratic Structure and Economic Performance Project, Department of Sociology. University of California, Berkeley, CA. 1997.

WADE, Robert. Governing the Market: Economic Theory and the Role of Government in Taiwan's Industrialization. Princeton, NJ: Princeton University Press, 1990.

Waterbury, John. The Egypt of Nasser and Sadat: The Political Economy of Two Regimes. Princeton, NJ: Princeton University Press, 1983.

Weber, Max [1904-1911]. Economy and Society. Editado por: Guenter Roth e Claus Wittich. New York: Beminster, 1968.

Williamson, Oliver. The Economic Institutions of Capitalism. New York: The Free Press, 1985.

\section{Apêndice A: A Escala de "Weberianismo"}

A Escala de Weberianismo foi criada a partir de 10 itens do questionário original. Os itens (com alternativas de respostas fixas abreviadas) são mostrados abaixo. 0 questionário completo e a recodificação utilizada para compilar a escala estão disponíveis em: <weber.ucsd.edu/ jrauch/webstate>.

As respostas individuais para as 10 questões (com exceção da questão 9) foram agregadas para criar um conjunto de dados no nível de país, no qual a pontuação de cada país era a média das respostas de todos os especialistas que responderam a todas as perguntas para aquele país. (A classificação de países na questão 9 foi baseada na avaliação do investigador sobre as respostas combinadas dos especialistas do país a duas questões relacionadas à iniciação e à seletividade dos exames para o serviço público). A média dos países para cada uma das 10 questões foi recodificada em duas ou três categorias, de tal modo a obter uma distribuição o mais igualitária possível dos países nas categorias. As 10 questões foram combinadas para formar uma escala. 
1) Qual das seguintes descrições melhor descreve o papel dessas agências na formulação da política econômica?

(1) Muitas políticas econômicas novas originaram-se dentro delas.

(2) Algumas políticas novas se originaram dentro delas.

(3) Elas raramente criam políticas novas.

2) Aproximadamente, qual é a proporção dos altos funcionários dessas agências que entraram no serviço público por intermédio de um sistema de exame formal?
(1) Menos de 30\%
(3) $60 \%-90 \%$
(2) $\quad 30 \%-60 \%$
(4) Mais de $90 \%$

3) Qual é aproximadamente o número modal de anos passados por um alto funcionário em uma dessas agências em sua carreira?
(1) 1-5 anos
(3) 10-20 anos
(2) 5-10 anos
(4) A carreira inteira

4) Quais são as perspectivas de promoção que uma pessoa que ingressa em uma dessas agências, mediante um exame para o serviço público no início de sua carreira, pode ter? Assumindo que há pelo menos meia dúzia de níveis entre uma posição no nível de entrada e a direção da agência, como você caracterizaria as possibilidades de subir na carreira dentro da agência? [NB, mais de uma pode ser aplicada]

(1) Na maior parte dos casos, subirá um ou dois níveis.

(2) Na maior parte dos casos, subirá três ou quatro níveis.

(3) Subirá vários níveis até o nível logo abaixo dos casos de indicação política.

(4) Em pelo menos alguns casos, subirá até o topo.

5) Quão comum é para um alto funcionário nessas agências passar parte substancial de sua carreira no setor privado, intercalando atividades do setor privado e público?
(1) Normal
(3) Não usual
(2) Frequente
(4) Quase nunca

6) Como você estimaria os salários (e as gratificações, não incluindo subornos ou outra fonte não legal de renda) dos altos funcionários dessas agências relativos aos dos administradores do setor privado com treinamento e responsabilidades aproximadamente comparáveis? 

(1) Menos de $50 \%$
(2) $50-80 \%$
(3) $80-90 \%$
(4) Equivalente
(5) Maior

7) Se subornos e outras gratificações não legais fossem incluídos, qual seria a sua proporção?
(1) Menos de $50 \%$
(2) $50-80 \%$
(3) $80-90 \%$
(4) Equivalente
(5) Maior

8) Durante o período em questão (aproximadamente entre os anos 1970-1990), qual foi a evolução da remuneração nessas agências com relação aos salários no setor privado?

(1) Diminuiu drasticamente.

(2) Diminui um pouco.

(3) Manteve a mesma posição.

(4) Melhorou sua posição.

9) Essa variável foi criada a partir da combinação de respostas obtidas junto a todos os especialistas dos países, baseada na avaliação da importância do exame de entrada para a burocracia do serviço público.

(0) Não há exames para o serviço público, ou os exames são de importância trivial.

(1) Ambígua, baseada nas respostas dos especialistas.

(2) Exames para o serviço público são um importante componente para a entrada na burocracia.

10) Entre os graduados da(s) universidade(s) mais conceituadas do país, a carreira pública é considerada como:

(1) A melhor posição possível

$(2,3)$ Depende das circunstâncias

(4) A segunda melhor opção 


\section{Apêndice B: Definições de Variáveis e Fontes dos Dados}

\begin{tabular}{|c|c|c|}
\hline Variável & Definição & Fonte \\
\hline $\begin{array}{l}\text { Porcentagem total de cres- } \\
\text { cimento em PIB per capita } \\
1970-1990\end{array}$ & $\begin{array}{l}\text { Porcentagem total do cresci- } \\
\text { mento em PIB real per capita } \\
\text { dos anos } 1970 \text { a } 1990 .\end{array}$ & $\begin{array}{l}\text { Penn World Tables (Mark 5.5) } \\
\text { (ver Summers e Heston, 1991) }\end{array}$ \\
\hline $\begin{array}{l}\text { Investimento doméstico, } \\
\text { 1985-1990 }\end{array}$ & $\begin{array}{l}\text { Média da razão anual do } \\
\text { investimento doméstico real } \\
\text { (privado mais público) e do } \\
\text { PIB real, durante o período } \\
\text { de } 1985 \text { a } 1990 \text {. }\end{array}$ & $\begin{array}{l}\text { Penn World Tables (Mark 5.5) } \\
\text { Tirado da atualização do } \\
\text { conjunto de dados de Barro } \\
\text { e Lee (1993) }\end{array}$ \\
\hline $\begin{array}{l}\text { Investimento doméstico, } \\
\text { 1965-1970 }\end{array}$ & $\begin{array}{l}\text { Média da razão anual do } \\
\text { investimento doméstico real } \\
\text { (privado mais público) e do } \\
\text { PIB real, durante o período } \\
\text { de } 1965 \text { a } 1970 \text {. }\end{array}$ & $\begin{array}{l}\text { Penn World Tables (Mark 5.5) } \\
\text { Tirado da atualização do } \\
\text { conjunto de dados de Barro } \\
\text { e Lee (1993) }\end{array}$ \\
\hline $\begin{array}{l}\text { Média de anos de estudo, } \\
1965^{a}\end{array}$ & $\begin{array}{l}\text { Média dos anos de estudo } \\
\text { da população total com } \\
\text { mais de } 25 \text { anos, } 1965 \text {. }\end{array}$ & $\begin{array}{l}\text { Conjunto de dados atuali- } \\
\text { zados de Barro e Lee (1993) }\end{array}$ \\
\hline $\begin{array}{l}\text { Consumo do governo, } \\
1970-1985\end{array}$ & $\begin{array}{l}\text { Média da razão anual da } \\
\text { despesa com consumo gover- } \\
\text { namental real líquido, do } \\
\text { gasto com defesa e com } \\
\text { educação do PIB real durante } \\
\text { o período de } 1970 \text { a } 1985 \text {. }\end{array}$ & $\begin{array}{l}\text { Conjunto de dados atuali- } \\
\text { zados de Barro e Lee (1993) }\end{array}$ \\
\hline $\begin{array}{l}\text { Média de revoluções, } \\
\text { 1970-1985 }\end{array}$ & $\begin{array}{l}\text { Número médio de revolu- } \\
\text { ções por ano no período } \\
\text { compreendido entre os anos } \\
1970 \text { a } 1985 \text {. }\end{array}$ & $\begin{array}{l}\text { Conjunto de dados atuali- } \\
\text { zados de Barro e Lee (1993) }\end{array}$ \\
\hline África & $\begin{array}{l}\text { Variável fictícia para os } \\
\text { países africanos subsaa- } \\
\text { rianos: Costa do Marfim, } \\
\text { Quênia, Nigéria e Zaire. }\end{array}$ & \\
\hline Leste Asiático & $\begin{array}{l}\text { Variável fictícia para os } \\
\text { quatro "Tigres Asiáticos": } \\
\text { Hong Kong, Coreia do Sul, } \\
\text { Cingapura e Taiwan. }\end{array}$ & \\
\hline América Latina & $\begin{array}{l}\text { Variável fictícia para os países } \\
\text { da América Latina: Argentina, } \\
\text { Brasil, Chile, Colômbia, Costa } \\
\text { Rica, República Dominicana, } \\
\text { Equador, Guatemala, Haiti, } \\
\text { México, Peru e Uruguai. }\end{array}$ & \\
\hline
\end{tabular}

a Dados para média de anos de estudo, em 1965, estavam indisponíveis nos casos do Egito, da Costa do Marfim, do Marrocos e da Nigéria. As observações para esses quatro países foram estimadas, servindose de dados da educação total obtidos de Nehru, Swanson e Ashutoh (1995). O coeficiente de correlação Pearson, entre essas duas variáveis, foi de $.08(p<.001)$. 


\section{Apêndice C: Pontuação da Escala de Weberianismo para 35 Países em Desenvolvimento}

\begin{tabular}{l|c|l|c}
\hline País & $\begin{array}{l}\text { Pontuação na Escala } \\
\text { de Weberianismo }\end{array}$ & País & $\begin{array}{l}\text { Pontuação na Escala } \\
\text { de Weberianismo }\end{array}$ \\
\hline Argentina & 3.8 & Malásia & 10.5 \\
\hline Brasil & 7.6 & Marrocos & 7.0 \\
\hline Chile & 5.0 & México & 8.5 \\
\hline Cingapura & 13.5 & Nigéria & 3.0 \\
\hline Colômbia & 8.5 & Paquistão & 11.0 \\
\hline Coreia do Sul & 13.0 & Peru & 5.0 \\
\hline Costa Rica & 9.0 & Portugal & 5.0 \\
\hline Costa do Marfim & 8.0 & Quênia & 1.0 \\
\hline Egito & 7.8 & República Dominicana & 2.0 \\
\hline Espanha & 10.0 & Síria & 3.8 \\
\hline Equador & 4.0 & Sri Lanka & 8.0 \\
\hline Filipinas & 6.0 & Tailândia & 8.0 \\
\hline Grécia & 10.0 & Taiwan & 12.0 \\
\hline Guatemala & 3.0 & Tunísia & 9.0 \\
\hline Haiti & 4.0 & Turquia & 7.0 \\
\hline Hong Kong & 11.0 & Uruguai & 4.5 \\
\hline Índia & 10.0 & Zaire & 4.0 \\
\hline Israel & 7.0 & & \\
\hline
\end{tabular}

Peter Evans

Professor Titular e Diretor do Departamento de Sociologia da University of California, em Berkeley. Seus recentes livros incluem: State-Society Synergy: Government Action and Social Capital in Development (coleção editada, Berkeley, CA: University of California, Berkeley, International and Area Studies Publications, 1997) e Embedded Autonomy: States and Industrial Transformation. (Princeton, NJ: Princeton University Press, 1995). Ele está atualmente trabalhando em uma coleção editada com título Livable Cities: The Politics of Urban Livelihood and Sustainability. Contato: pevans@socrates.berkeley.edu

James E. Rauch

Professor de Economia da University of California, San Diego e Pesquisador Associado do National Bureau of Economic Research. Co-autor (com Gerald M. Meier) do livro Leading Issues in Economic Development (7a edição, Oxford University Press) e co-editor (com Robert C. Feenstra) do Symposium on Business and Social Networks in International Trade, edição especial do Journal of International Economics (v. 48, no 1, junho de 1999). Atualmente está trabalhando em volume de uma conferência com título: Networks and Markets. Contato: jrauch@ucsd.edu 
RSP 